\title{
Paenibacillus pasadenensis sp. nov. and Paenibacillus barengoltzii sp. nov., isolated from a spacecraft assembly facility
}

\author{
Shariff Osman, ${ }^{1}$ Masataka Satomi ${ }^{1,2}$ and Kasthuri Venkateswaran ${ }^{1}$ \\ ${ }^{1}$ Biotechnology and Planetary Protection Group, Jet Propulsion Laboratory, California Institute \\ of Technology, 89-2; Biotechnology and Planetary Protection Group, 4800, Oak Grove Dr., \\ Pasadena, CA 91109, USA \\ ${ }^{2}$ National Research Institute of Fisheries Science, Fisheries Research Agency, Yokohama, \\ 236-8648, Japan
}

Correspondence

Shariff Osman

sosman@jpl.nasa.gov
Spacecraft designed for the robotic exploration of extraterrestrial systems potentially capable of sustaining life must be assembled in clean rooms following stringent qualitycontrol practices that are aimed towards minimizing surface bioburden. Studies utilizing the NASA standard assay have shown that members of the spore-forming genus Bacillus are the most frequently isolated microbes on spacecraft and associated facility surfaces (La Duc et al., 2003; Puleo et al., 1977). During a survey of the Jet Propulsion Laboratory Spacecrat Assembly Facility (JPL-SAF) in December 2000, 30 strains of spore-forming microbes were systematically isolated and identified using both phenotypic tests and $16 \mathrm{~S}$ rRNA gene sequence analysis (Fig. 1). Phylogenetic affiliations revealed that all of these strains were Gram-positive bacteria belonging to the genera Bacillus (23 isolates comprising nine species), Filibacter, Sporosarcina, Paenibacillus

Abbreviation: JPL-SAF, Jet Propulsion Laboratory Spacecraft Assembly Facility.

The GenBank/EMBL/DDBJ accession numbers for the 16S rRNA gene sequences of the Paenibacillus strains investigated in this study are given in Table 1. and Streptomyces. The most abundant species was Bacillus pumilus (six isolates) followed by Bacillus megaterium (three isolates). The 16S rRNA gene sequences of two isolates, SAFN $-007^{\mathrm{T}}$ and SAFN- $016^{\mathrm{T}}$, exhibited $>95 \%$ similarity to members of the genus Paenibacillus. As this was the first incidence of Paenibacillus species reported in the JPL-SAF, both strains were further characterized using a polyphasic taxonomic approach.

The JPL-SAF consists of both classified and unclassified clean room locations. The classified portions of this facility are maintained as Class $100 \mathrm{~K}$ clean rooms (maximum number of particles $>0.5 \mu \mathrm{m}$ in 1 cubic foot of air; ISO, 1999). Polyester swabs were used to collect samples from 200 locations at various times from both unclassified (entrance floors, ante-room and air-lock) and classified (floors, cabinet tops and air) surfaces within the JPL-SAF; specific details have been reported elsewhere (Venkateswaran et al., 2001). The collected swab samples were sonicated $(25 \mathrm{kHz})$ for $2 \mathrm{~min}$ and aliquots were either left untreated or were subjected to heat shock $\left(80^{\circ} \mathrm{C}\right.$ for $\left.15 \mathrm{~min}\right)$ to kill vegetative cells. Heat-shocked samples were pour-plated in tryptic soy agar (TSA) and grown at $32{ }^{\circ} \mathrm{C}$ for 2 days. Samples not 


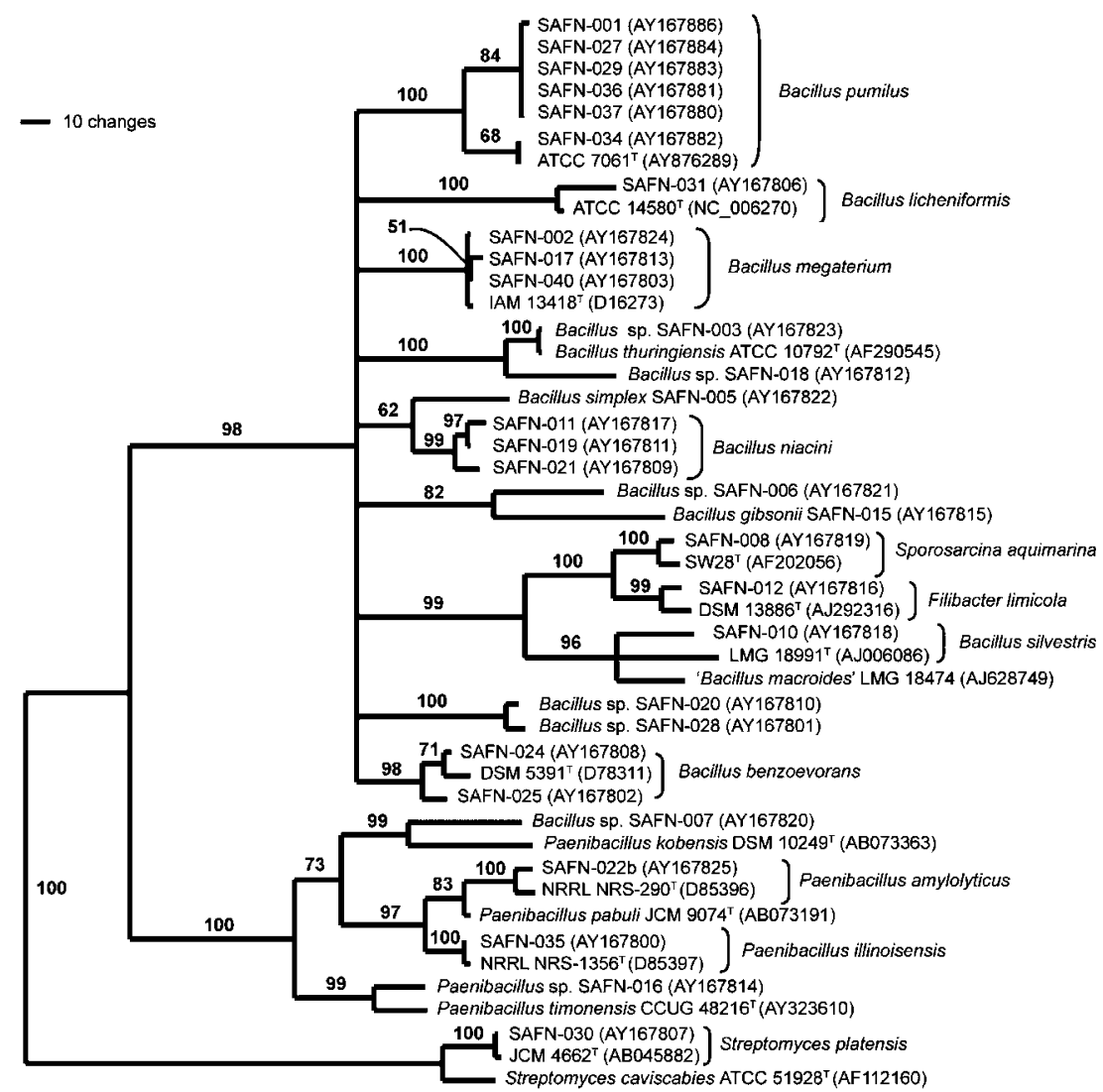

Fig. 1. Phylogenetic tree of bacterial isolates from the JPL-SAF based on 16S rRNA gene sequence comparisons. Branching percentage values were determined using 1000 bootstraps. Bar, 10 changes. subjected to heat shock were spread-plated on R2A medium and incubated at $25^{\circ} \mathrm{C}$ for 7 days.

The bacterial strains analysed in this study are shown in Table 1. A set of related type strains were received as gifts from the Agricultural Research Service Culture Collection (http://nrrl.ncaur.usda.gov) or purchased from the Swedish Culture Collection (CCUG), University of Göteborg, Sweden, and used as reference strains. All isolates were maintained in TSA stabs (Becton Dickinson) at room temperature for short-term analysis and in glycerol at $-80{ }^{\circ} \mathrm{C}$ for long-term storage. Liquid cultures were grown in tryptic soy broth (TSB) (Becton Dickinson) and incubated at $32^{\circ} \mathrm{C}$ with vigorous aerobic shaking for an appropriate period of time. Representative strains have been deposited in the American Type Culture Collection (ATCC) and the National Institute of Technology and Evaluation, Biological Resource Center (NBRC), Japan (Table 1).

Cellular morphology, motility, Gram-staining and the refractile nature of the endospores were examined by phase-contrast microscopy. A nutrient sporulation medium was used to produce spores as described previously (La Duc et al., 2003; Nicholson \& Setlow, 1990; Schaeffer et al., 1965). Routine biochemical tests were carried out using commercially available API kits (API 20NE and API 20E), inoculated according to the manufacturer's instructions (bioMérieux). Metabolic profiling was performed using the Biolog 96-well microplate test for the oxidation of 95 different carbon sources (Biolog).
Phenotypic characteristics of the novel isolates SAFN-007 ${ }^{\mathrm{T}}$, SAFN-016 ${ }^{\mathrm{T}}$ and SAFN-125 and other closely related Paenibacillus species are presented in Table 2. Strain SAFN-007 ${ }^{\mathrm{T}}$ did not reduce nitrate, was positive for Voges-Proskauer tests, liquefied gelatin and assimilated arabinose, glucose, maltose, mannose, malate, mannitol and $N$-acetylglucosamine. However, strains SAFN-016 ${ }^{\mathrm{T}}$ and SAFN-125 did not assimilate any of the carbon substrates tested apart from gluconate. Strain SAFN-007 ${ }^{\mathrm{T}}$ did not assimilate gluconate as a sole carbon source. The Biolog-based carbon substrate profiles of the novel strains did not match those of any of the Bacillus or Paenibacillus species provided in the manufacturer's database. The phenotypic characteristics of Paenibacillus kobensis, the closest neighbour of strain SAFN-007 ${ }^{\mathrm{T}}$ according to $16 \mathrm{~S}$ rRNA gene sequences, differed from those of strain SAFN-007 ${ }^{\mathrm{T}}$ as regards nitrate reduction, urea hydrolysis, malate assimilation and acid production from sucrose and L-arabinose (Kanzawa et al., 1995) (Table 2). These differences strongly support the conclusion of the phylogenetic analysis that strain $\mathrm{SAFN}-007^{\mathrm{T}}$ represents a novel species in the genus Paenibacillus. When strains SAFN$016^{\mathrm{T}}$ and SAFN-125 were tested, no significant colouration of tetrazolium dye was seen. This was in agreement with API test strips in which the majority of carbon substrates tested were not assimilated by either of these strains (Table 2). Significant characteristic phenotype differences between strains SAFN-016 ${ }^{\mathrm{T}}$ and SAFN-125 and Paenibacillus timonensis CCUG $48216^{\mathrm{T}}$ are nitrate reduction, acid production from sugars and the assimilation of several carbohydrates, 
Table 1. Source and isolation of strains used in this study

\begin{tabular}{|c|c|c|}
\hline Strain & $\begin{array}{c}\text { 16S rRNA } \\
\text { gene sequence } \\
\text { accession no. }\end{array}$ & Source \\
\hline \multicolumn{3}{|l|}{ Paenibacillus amylolyticus } \\
\hline NRRL NRS $-290^{\mathrm{T}}$ & D85396 & Soil \\
\hline SAFN-022b & AY167825 & Clean room floor, JPL-SAF, 2000 \\
\hline \multicolumn{3}{|l|}{ Paenibacillus barengoltzii } \\
\hline $\begin{array}{l}\text { SAFN-016 }{ }^{\mathrm{T}}\left(=\text { ATCC BAA- } 1209^{\mathrm{T}}=\right. \\
\left.\text { NBRC } 101215^{\mathrm{T}}\right)\end{array}$ & AY167814 & Clean room floor, JPL-SAF, 2000 \\
\hline SAFN-125 (=ATCC BAA-1210) & DQ124699 & Clean room floor, JPL-SAF, 2001 \\
\hline \multicolumn{3}{|l|}{ Paenibacillus illinoisensis } \\
\hline NRRL NRS- $1356^{\mathrm{T}}$ & D85397 & Soil \\
\hline SAFN-035 & AY167800 & Clean room floor, JPL-SAF, 2000 \\
\hline Paenibacillus macerans NRRL B- $172^{\mathrm{T}}$ & X57306 & Unknown \\
\hline \multicolumn{3}{|l|}{ Paenibacillus pabuli } \\
\hline NRRL NRS-924 ${ }^{\mathrm{T}}$ & AB045094 & Unknown \\
\hline SAFN-068 & DQ124700 & Clean room floor, JPL-SAF, 2001 \\
\hline $\begin{array}{l}\text { Paenibacillus pasadenensis SAFN-007 } \\
\quad\left(=\text { ATCC BAA- } 1211^{\mathrm{T}}=\text { NBRC } 101214^{\mathrm{T}}\right)\end{array}$ & AY167820 & Clean room floor, JPL-SAF, 2000 \\
\hline Paenibacillus polymyxa NRRL B- $4317^{\mathrm{T}}$ & AJ320493 & Unknown \\
\hline Paenibacillus timonensis CCUG $48216^{\mathrm{T}}$ & AY323610 & Blood, France, 2002 \\
\hline Stenotrophomonas maltophila SAFR-173 & DQ124701 & Clean room floor, JPL-SAF, 2001 \\
\hline
\end{tabular}

as shown in Table 2. Phenotypic characteristics of the novel Paenibacillus species are given in the species descriptions.

To purify DNA, cells were grown overnight in TSB at $30^{\circ} \mathrm{C}$ and harvested by centrifugation. Pellets were resuspended in TE buffer ( $\mathrm{pH} \mathrm{8.0)} \mathrm{supplemented} \mathrm{with} 1 \%$ Triton X-100 and boiled to destroy cell walls. The 16S rRNA gene was PCR-amplified with universal primer sets as previously described (La Duc et al., 2004), purified on Qiagen filtration columns and sequenced. The identity of a given PCR product was verified by bidirectional sequencing. The phylogenetic relationships of the organisms investigated in this study were determined by comparison of individual $16 \mathrm{~S}$ rRNA gene sequences with other sequences in public databases using the BLAST algorithm (Altschul et al., 1990). Evolutionary trees were constructed with PAUP software, following maximum parsimony parameters (Swofford, 1990). Alignment gaps, primer regions for PCR amplification and unidentified base positions were not taken into consideration for the calculations. The robustness of the topology of the phylogenetic trees was evaluated by a bootstrap analysis with 1000 replications. GenBank accession numbers for the 16S rRNA gene sequences analysed in this study are shown in Table 1.

A phylogenetic tree based on $16 \mathrm{~S}$ rRNA gene sequences (Fig. 2) showed that the novel isolates clustered with members of the genus Paenibacillus, the nearest neighbours being $P$. kobensis DSM $10249^{\mathrm{T}}$ for strain SAFN-007 ${ }^{\mathrm{T}}$ and Paenibacillus timonensis CCUG $48216^{\mathrm{T}}$ for strains SAFN$016^{\mathrm{T}}$ and SAFN-0125. Strain SAFN-007 ${ }^{\mathrm{T}}$ showed only $95 \cdot 2 \% 16 \mathrm{~S}$ rRNA gene sequence similarity with $P$. kobensis
DSM $10249^{\mathrm{T}}$. Strains SAFN-016 ${ }^{\mathrm{T}}$ and SAFN-125 exhibited $98 \% 16$ S rRNA gene sequence similarities with $P$. timonensis CCUG $48216^{\mathrm{T}}$ and $97 \%$ with Paenibacillus macerans NRRL $\mathrm{B}-172^{\mathrm{T}}$ and shared $99 \cdot 8 \%$ sequence similarity with each other. The phylogenetic distances between strain SAFN$007^{\mathrm{T}}$ and its nearest neighbours in the genus Paenibacillus suggest that this strain represents a novel species (Wayne, 1988). Since strains SAFN- $016^{\mathrm{T}}$ and SAFN-125 are so closely related to their nearest neighbours on the basis of 16S rRNA gene sequences, further study was necessary to confirm their taxonomic position. Gene sequence similarities between the two novel Paenibacillus species and the 18 other members of the genus Paenibacillus ranged from 92 to $98 \%$. The two novel species showed only $86-87 \%$ gene sequence similarity to Bacillus subtilis.

PCR primer sets specific for strains SAFN $-007^{\mathrm{T}}$ and SAFN$016^{\mathrm{T}}$ were designed to screen the large collection of bacteria ( $\sim 400$ strains) isolated from the JPL-SAF for similar strains. The 16S rRNA gene sequences from both novel strains, SAFN- $016^{\mathrm{T}}$ and SAFN-007 ${ }^{\mathrm{T}}$, were compared with those of their closest related Paenibacillus species. Species-specific primers were designed for each group and tested against DNA extracts from both the novel strains and the type strains listed in Table 1. Isolates similar to strain SAFN-007 ${ }^{\mathrm{T}}$ were screened for by using primers $172 \mathrm{Fb}\left(5^{\prime}\right.$-CCAGATACGCGATCTTC-3') and 649R (5'-GTTTCCCGTGCGACTTGG-3'). SAFN-016 ${ }^{\mathrm{T}}$ group isolates were selected for using primers $173 \mathrm{Fa}$ (5'-CCGGATACGCAAGTCTC-3') and $1161 \mathrm{Rb}\left(5^{\prime}\right.$-CTAGAGTGCCCAACCTACT- $\left.3^{\prime}\right)$. The PCR conditions were as follows: denaturation for $1 \mathrm{~min}$ at $95^{\circ} \mathrm{C}$, annealing for $2 \mathrm{~min}$ at $55^{\circ} \mathrm{C}$ and elongation 
Table 2. Phenotypic characterization of the novel Paenibacillus strains and closely related species

Strains: 1, Strain SAFN-007 ${ }^{\mathrm{T}}$; 2, P. kobensis IFO $15729^{\mathrm{T}} ; 3, P$. pabuli NRRL NRS- $924^{\mathrm{T}}$; 4 , strain SAFN-016 ${ }^{\mathrm{T}}$; 5 , strain SAFN-125; 6, P. timonensis CCUG $48216^{\mathrm{T}} ; 7$, P. amyloyticus NRRL B- $14945^{\mathrm{T}}$; 8, P. illinoisensis NRRL NRS- $1356^{\mathrm{T}} ; 9, P$. macerans NRRL B- $172^{\mathrm{T}}$; 10, $P$. polymyxa NRRL B- $4317^{\mathrm{T}}$. All data are from this study unless otherwise indicated. All strains were Gram-positive rods, motile, spore-forming and positive for the production of catalase and oxidase. All strains hydrolysed ONPG and aesculin. None of the strains produced $\mathrm{H}_{2} \mathrm{~S}$, indole or tryptophan. ND, Not determined; w, weak reaction.

\begin{tabular}{|c|c|c|c|c|c|c|c|c|c|c|}
\hline Characteristic & 1 & $2^{\star}$ & 3 & 4 & 5 & 6 & 7 & 8 & 9 & 10 \\
\hline Nitrate to nitrite & - & $+^{a}$ & + & + & + & - & - & - & + & + \\
\hline Arginine dihydrolase & $\mathrm{W}$ & $-{ }^{b}$ & - & - & - & - & - & - & - & - \\
\hline Gelatinase & + & $-{ }^{b}$ & - & - & - & - & - & - & + & + \\
\hline \multicolumn{11}{|l|}{ Assimilation of: } \\
\hline $\mathrm{N}$-Acetylglucosamine & + & $+^{c}$ & + & - & - & + & - & + & - & - \\
\hline Arabinose & + & $++^{a}$ & + & - & - & + & + & + & + & + \\
\hline Gluconate & - & $-{ }^{c}$ & + & + & + & + & + & + & + & + \\
\hline Glucose & + & $++^{a}$ & + & - & - & + & + & + & + & + \\
\hline Malate & + & $-^{a}$ & - & - & - & - & - & - & - & - \\
\hline Maltose & + & $+^{c}$ & + & - & $+1-$ & + & + & + & + & - \\
\hline Mannitol & + & $-^{c}$ & + & - & - & - & + & + & + & + \\
\hline Mannose & + & $-^{c}$ & + & - & - & + & + & - & + & + \\
\hline Acetoin production & + & $+^{a}$ & + & - & - & - & ND & ND & ND & + \\
\hline \multicolumn{11}{|l|}{ Acid production from: } \\
\hline Amylose & - & $-{ }^{b}$ & - & - & - & + & ND & ND & ND & - \\
\hline Arabinose & - & $++^{a}$ & - & - & - & + & ND & ND & ND & - \\
\hline Mannitol & - & $-^{a}$ & - & - & - & - & $\mathrm{ND}$ & $\mathrm{ND}$ & ND & + \\
\hline Melibiose & - & $-^{a}$ & - & - & - & + & ND & ND & ND & - \\
\hline Rhamnose & - & $-{ }^{a}$ & - & - & - & + & ND & ND & ND & - \\
\hline Sucrose & - & $+^{a}$ & - & - & - & - & $\mathrm{ND}$ & $\mathrm{ND}$ & $\mathrm{ND}$ & - \\
\hline
\end{tabular}

${ }^{*}$ Data from: a, Kanzawa et al. (1995); b, Smerda et al. (2005); c, Dasman et al. (2002).

for $3 \mathrm{~min}$ at $72{ }^{\circ} \mathrm{C}$ for 32 cycles using a thermal cycler (MJ Research).

Three additional strains produced PCR-amplified products with either the SAFN- $016^{\mathrm{T}}$ - or SAFN- $007^{\mathrm{T}}$-specific primer sets. Strain SAFN-068 (isolated in March 2001) yielded a $477 \mathrm{bp}$ amplicon specific for strain SAFN- $007^{\mathrm{T}}$. Strains SAFN-125 (isolated June 2001) and SAFR-173 (isolated September 2001) exhibited 988 bp amplicons specific for strain SAFN-016 ${ }^{\mathrm{T}}$. Although the PCR-amplified products from strains SAFN-068 and SAFR-173 were faint in comparison with that of strain SAFN-125 when visualized on agarose gels, the full-length 16S rRNA genes of all three isolates were amplified and sequenced. Strain SAFN-068 was identified as Paenibacillus pabuli based on 16S rRNA gene sequence similarity (99.7\%), API 20NE, 20E and Biolog analyses. Strain SAFR-173 was found to be closely related to Stenotrophomonas maltophilia ( $98 \cdot 2 \%$ gene sequence similarity). As the most closely related species to strain SAFN-173 was Gram-negative, phenotypic characteristics were not determined. This confirmed that strains exhibiting faint bands were not the intended sequence targets, but rather were the result of non-specific amplification. Strain SAFN125 was the only isolate found that closely matched the $16 \mathrm{~S}$ rRNA gene sequence of strain SAFN- $016^{\mathrm{T}}(99 \cdot 8 \%$ similarity). Species-specific PCR screening did not reveal any additional strains for the SAFN- $007^{\mathrm{T}}$ isolate.

For DNA-DNA hybridization analysis, cells were suspended in $0 \cdot 1 \mathrm{M}$ EDTA ( $\mathrm{pH} 8 \cdot 0$ ) and cell walls were digested by lysozyme treatment (final concentration $2 \mathrm{mg} \mathrm{ml}^{-1}$ ). DNA was isolated following standard procedures (Johnson, 1981). DNA-DNA hybridization was conducted by microplate hybridization methods (Ezaki et al., 1989) with photobiotin labelling and colorimetric detection, using 1,2-phenylenediamine (Sigma) as the substrate and streptavidin-peroxidase conjugate (Boehringer Mannheim) as the colorimetric substrate (Satomi et al., 1997). Since the 16S rRNA gene sequences of strains SAFN- $016^{\mathrm{T}}$ and SAFN-125 showed high similarity values with $P$. timonensis $(98 \%)$ and $P$. macerans (97\%), type strains of several Paenibacillus were included and a DNA-DNA hybridization study was performed. Due to the very low gene sequence similarity revealed between strain SAFN-007 ${ }^{\mathrm{T}}$ and P. kobensis, DNA-DNA hybridization was deemed to be unnecessary. The results of this study are given in Table 3. Strain SAFN-016 ${ }^{\mathrm{T}}$ exhibited $\sim 38 \%$ DNADNA relatedness with $P$. timonensis CCUG $48216^{\mathrm{T}}$ and $P$. macerans NRRL B-172 ${ }^{\mathrm{T}}$. This strongly supports the claim that the isolates represent two novel species within the genus Paenibacillus.

Although phenotypic characterization differentiated these novel species from their most closely related phylogenetic neighbours, a metabolic fingerprint based on Biolog results was not available in the manufacturer's database to identify the novel bacterial isolates. Of the genotypic analyses performed, 16S rRNA gene sequence analysis unambiguously discriminated strain SAFN- $007^{\mathrm{T}}$ as representing a novel Paenibacillus species, but DNA-DNA hybridization was required to describe strains SAFN-016 ${ }^{\mathrm{T}}$ and SAFN-125. Based on the results of the polyphasic study described above, it is suggested that the three strains isolated from the spacecraft assembly facilities represent two novel species within the genus Paenibacillus. The names Paenibacillus pasadenensis sp. nov. and Paenibacillus barengoltzii sp. nov. are proposed for strain SAFN- $007^{\mathrm{T}}$ and strains SAFN- $016^{\mathrm{T}}$ and SAFN-125, respectively.

\section{Description of Paenibacillus pasadenensis sp. nov.}

Paenibacillus pasadenensis (pa.sa.den.en'sis. N.L. masc. adj. pasadenensis referring to Pasadena, the city in which the JPL-SAF is located).

Cells are Gram-positive rods, $0 \cdot 5-0 \cdot 8 \times 3 \cdot 0-5 \cdot 0 \mu \mathrm{m}$ in size and motile by means of peritrichous flagella. Ellipsoidal spores are formed in swollen sporangia. Colonies are flat, 


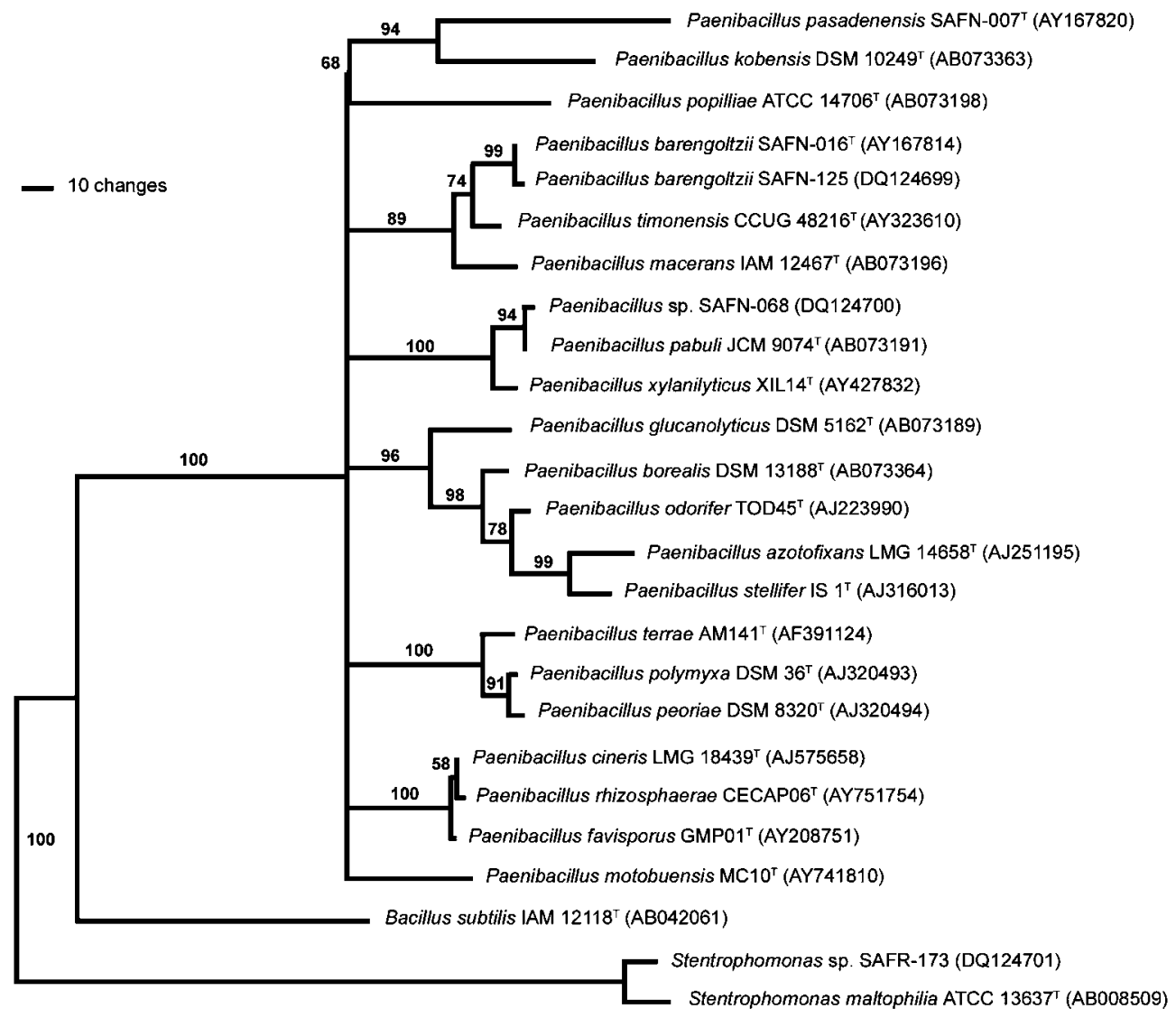

Fig. 2. Phylogenetic tree of novel Paenibacillus isolates from the JPL-SAF based on $16 \mathrm{~S}$ rRNA gene sequence similarity. Branching values determined using 1000 bootstraps. Bar, 10 changes.

smooth, circular, entire and brownish yellow. No soluble pigment is produced on nutrient agar. Catalase and oxidase tests are positive. Acetylmethylcarbinol is produced (as determined by the Voges-Proskauer reaction). Hydrogen sulfide and indole are not produced. Nitrate is not reduced to nitrite. Gelatin is liquefied, aesculin is hydrolysed and $\beta$-galactosidase is produced. Growth occurs in the presence of $2 \% \mathrm{NaCl}$ and $0 \cdot 001 \%$ lysozyme. Growth is inhibited by

Table 3. DNA-DNA hybridization among Paenibacillus strains isolated from JPL-SAF

ND, Not determined.

\begin{tabular}{|c|c|c|c|c|c|c|}
\hline \multirow[t]{2}{*}{ Strain } & \multicolumn{6}{|c|}{ DNA-DNA reassociation value $(\%)$} \\
\hline & 1 & 2 & 3 & 4 & 5 & 6 \\
\hline 1. Paenibacillus pasadenensis SAFN-007 ${ }^{\mathrm{T}}$ & 100 & 18 & ND & ND & 6 & 8 \\
\hline 2. Paenibacillus barengoltzii SAFN- $016^{\mathrm{T}}$ & 10 & 100 & 89 & 34 & 10 & 9 \\
\hline 3. Paenibacillus barengoltzii SAFN- 125 & $\mathrm{ND}$ & 88 & 100 & 37 & ND & $\mathrm{ND}$ \\
\hline 4. P. timonensis CCUG $48216^{\mathrm{T}}$ & $\mathrm{ND}$ & 36 & 38 & 100 & $\mathrm{ND}$ & $\mathrm{ND}$ \\
\hline 5. P. amylolyticus SAFN-022b & 7 & 10 & ND & $\mathrm{ND}$ & 100 & 26 \\
\hline 6. P. illinoisensis SAFN-035 & 8 & 11 & $\mathrm{ND}$ & $\mathrm{ND}$ & 39 & 100 \\
\hline P. amylolyticus NRRL B-14945 ${ }^{\mathrm{T}}$ & 10 & 12 & ND & $\mathrm{ND}$ & 88 & 24 \\
\hline P. illinoisensis NRRL NRS- $1356^{\mathrm{T}}$ & 6 & 15 & $\mathrm{ND}$ & $\mathrm{ND}$ & 47 & 88 \\
\hline P. macerans NRRL B-172 ${ }^{\mathrm{T}}$ & 12 & 38 & ND & $\mathrm{ND}$ & 4 & 7 \\
\hline P. pabuli NRRL NRS-924 ${ }^{\mathrm{T}}$ & 7 & 11 & ND & ND & 50 & 25 \\
\hline P. polymyxa NRRL B- $4317^{\mathrm{T}}$ & 7 & 7 & ND & ND & 8 & 7 \\
\hline
\end{tabular}


$3 \% \mathrm{NaCl}$. Utilizes $\alpha$-cyclodextrin, D-cellobiose, D-fructose, maltose, D-melibiose, methyl $\beta$-D-glucoside, D-ribose, pyruvic acid, L-alanyl glycine and L-serine. Acid is not produced from D-glucose.

The type strain, SAFN $-007^{\mathrm{T}}\left(=\right.$ ATCC BAA- $1211^{\mathrm{T}}=\mathrm{NBRC}$ $101214^{\mathrm{T}}$ ), was isolated from the entrance floor of the JPL-SAF, Pasadena, CA, USA.

\section{Description of Paenibacillus barengoltzii sp. nov.}

Paenibacillus barengoltzii (ba.ren.gol'tzi.i. N.L. gen. n. barengoltzii referring to Jack Barengoltz, a well-known American physicist and NASA planentary protection scientist).

Cells are Gram-positive rods, $0 \cdot 5-0 \cdot 8 \times 3 \cdot 0-5 \cdot 0 \mu \mathrm{m}$ in size, strictly aerobic and motile by means of peritrichous flagella. Ellipsoidal spores are formed in swollen sporangia. Colonies are flat, smooth, circular, entire and brownish yellow. No soluble pigment is produced on nutrient agar. Catalase and oxidase tests are positive. Acetylmethylcarbinol is produced (as determined by the Voges-Proskauer reaction). Hydrogen sulfide and indole are not produced. Nitrate is reduced to nitrite. Gelatin is not liquefied, aesculin is hydrolysed and $\beta$-galactosidase is produced. Growth occurs between 10 and $50{ }^{\circ} \mathrm{C}$ and at $\mathrm{pH} 4 \cdot 5-9 \cdot 0$. Optimum growth occurs at $37^{\circ} \mathrm{C}$ and at $\mathrm{pH} 7 \cdot 0$. Growth occurs in the presence of $2 \% \mathrm{NaCl}$ and $0.001 \%$ lysozyme. Growth is inhibited by $5 \% \mathrm{NaCl}$. Of the carbon substrates tested, only gluconate is utilized. Acid is not produced from D-glucose.

The type strain, SAFN $-016^{\mathrm{T}}\left(=\right.$ ATCC BAA $-1209^{\mathrm{T}}=\mathrm{NBRC}$ $101215^{\mathrm{T}}$ ) was isolated from clean room floors of the JPL-SAF, Pasadena, CA, USA. Strain SAFN-125 (=ATCC BAA-1210) is a reference strain.

\section{Acknowledgements}

The research described in this publication was carried out at the Jet Propulsion Laboratory, California Institute of Technology, under a contract with the National Aeronautics and Space Administration. This research was funded by NRA-ROSS-2001 awarded to K. V. We are grateful to the NASA Planetary Protection Office for funding. We would like to thank Alexander Rooney for providing a number of the Paenibacillus strains used in this study. We are thankful to all the members of the Biotechnology and Planetary Protection Group, JPL, for sampling, analysis and discussion. We thank C. Echeverria, Myron La Duc and Wayne Schubert for technical assistance.

\section{References}

Altschul, S. F., Gish, W., Miller, W., Myers, E. W. \& Lipman, D. J. (1990). Basic local alignment search tool. J Mol Biol 215, 403-410.
Dasman, Kajiyama, S., Kawasaki, H., Yagi, M., Seki, T., Fukusaki, E. \& Kobayashi, A. (2002). Paenibacillus glycanilyticus sp. nov., a novel species that degrades heteropolysaccharide produced by the cyanobacterium Nostoc commune. Int J Syst Evol Microbiol 52, 1669-1674.

Ezaki, T., Hashimoto, Y. \& Yabuuchi, E. (1989). Fluorometric deoxyribonucleic acid-deoxyribonucleic acid hybridization in microdilution wells as an alternative to membrane filter hybridization in which radioisotopes are used to determine genetic relatedness among bacterial strains. Int J Syst Bacteriol 39, 224-229.

ISO (1999). ISO 14644-1, Cleanrooms and associated controlled environments. Part 1: Classification of air cleanliness. http://www.iest.org/iso/ isol.htm

Johnson, J. L. (1981). Genetic characterization. In Manual of Methods for General Bacteriology, p. 450-472. Edited by P. Gerhardt, R. G. E. Murray, R. N. Costilaw, E. W. Nester, W. A. Wood, N. R. Krieg \& G. B. Phillips. Washington, DC: American Society for Microbiology.

Kanzawa, Y., Harada, A., Takeuchi, M., Yokota, A. \& Harada, T. (1995). Bacillus curdlanolyticus sp. nov. and Bacillus kobensis sp. nov., which hydrolyze resistant curdlan. Int J Syst Bacteriol 45, 515-521.

La Duc, M. T., Nicholson, W., Kern, R. \& Venkateswaran, K. (2003). Microbial characterization of the Mars Odyssey spacecraft and its encapsulation facility. Environ Microbiol 5, 977-985.

La Duc, M. T., Satomi, M. \& Venkateswaran, K. (2004). Bacillus odysseyi sp. nov., a round-spore-forming bacillus isolated from the Mars Odyssey spacecraft. Int J Syst Evol Microbiol 54, 195-201.

Nicholson, W. \& Setlow, P. (1990). Sporulation, germination and outgrowth. In Molecular Biological Methods for Bacillus, pp. 391-450. Edited by C. R. Harwood \& S. M. Cutting. Chichester: Wiley.

Puleo, J. R., Fields, N. D., Bergstrom, S. L., Oxborrow, G. S., Stabekis, P. D. \& Koukol, R. (1977). Microbiological profiles of the Viking spacecraft. Appl Environ Microbiol 33, 379-384.

Satomi, M., Kimura, B., Mizoi, M., Sato, T. \& Fujii, T. (1997). Tetragenococcus muriaticus sp. nov., a new moderately halophilic lactic acid bacterium isolated from fermented squid liver sauce. Int $J$ Syst Bacteriol 47, 832-836.

Schaeffer, P., Millet, J. \& Aubert, J. P. (1965). Catabolic repression of bacterial sporulation. Proc Natl Acad Sci U S A 54, 704-711.

Smerda, J., Sedlacek, I., Pacova, Z., Durnova, E., Smiskova, A. \& Havel, L. (2005). Paenibacillus mendelii sp. nov., from surfacesterilized seeds of Pisum sativum L. Int J Syst Evol Microbiol 55, 2351-2354.

Swofford, D. (1990). PAUP: phylogenetic analysis using parsimony, version 2.0. Illinois Natural Survey, Champaign, IL, USA.

Venkateswaran, K., Satomi, M., Chung, S., Kern, R., Koukol, R., Basic, C. \& White, D. (2001). Molecular microbial diversity of a spacecraft assembly facility. Syst Appl Microbiol 24, 311-320.

Wayne, L. G. (1988). International Committee on Systematic Bacteriology: announcement of the report of the ad hoc Committee on Reconciliation of Approaches to Bacterial Systematics. Zentralbl Bakteriol Mikrobiol Hyg $[A]$ 268, 433-434. 